lyophilised powder, which has to be dissolved separately for each examination.

The second generation of low osmolar radiological contrast media (iohexol, iopamidol, ioxaglate) have been introduced into clinical practice within the last two years and they have substantial advantages over metrizamide. ${ }^{1}$ They are about one sixth of its cost (but still three to five times the cost of conventional ionic radiological contrast media); they are autoclavable in solution and are therefore supplied in sterile ampouled solutions; and their low osmolality and intravascular toxicity are similar to those of metrizamide.

Low osmolar products have very substantial advantages for intravascular use. Firstly, all varieties of arteriography (including aortography and cerebral, femoral, and brachial arteriography) are rendered virtually painless. ${ }^{1}$ The new products convert what used often to be very uncomfortable arteriography into a painless procedure, readily acceptable to the patient with the minimum or no premedication. Indeed, general anaesthesia is no longer needed for radiological vascular studies except in some special clinical circumstances (such as the investigation of subarachnoid haemorrhage). With general anaesthesia no longer needed, the overall cost of radiological procedures is reduced-so is the time spent in hospital.

Among the less obvious advantages are less cardiac depression during coronary angiography and left ventriculography ${ }^{4}$ a smaller increase in the blood volume, probably slightly lower renal toxicity, and a probable reduction in those severe reactions of unknown mechanism generally called "anaphylactoid."

Very high doses of radiological contrast media are known to cause deterioration of renal function (manifested by oliguria, anuria, and azotaemia) in some patients with pre-existing renal impairment, especially diabetics. ${ }^{6}$ The new low osmolar radiological contrast media seem unlikely to have substantially less renal toxicity, and a dose of $200 \mathrm{ml}$ radiological contrast medium for a single study should be exceeded only after careful consideration of the clinical circumstances, particularly if renal function is already impaired.

The death rate from intravenous urography is probably between one in 20000 and one in 40000 examinations. ${ }^{7}$ The rate of these reactions seems lower with low osmolar radiological contrast media; the evidence suggests that the death rate has been reduced to about one in 40000 to 80000 intravenous urograms.

Replacing all conventional ionic radiological contrast media by the newer more physiological products has no disadvantages other than the cost-and the lesser distension of the urinary tract on intravenous urography owing to the reduced osmotic diuresis. The cost of radiological contrast media in Britain was about $£ 4$ million in 1983, of which $£ 2.5$ million was spent on conventional ionic radiological contrast media. Some half a million to one million intravenous urograms, enhanced CT scans, and arteriograms are performed in Britain each year, with about 25 deaths from adverse reactions. If deaths might be reduced to, say, 10 to 15 a year by substituting low osmolar radiological contrast media, the additional cost would be $£ 6$ million to $£ 9$ million . This suggests that the cost of preventing one death might be $£ 500000$. For comparison, the estimated annual cost for renal dialysis is $£ 10000$, which saves that patient's life for one year.

If, as seems likely, NHS finances are thought too limited at present to replace all conventional ionic radiological contrast media, then some guidelines might be considered indicating those patients with a priority claim to the less toxic but more expensive low osmolar radiological contrast media. The priority groups should probably include $(a)$ all patients undergoing painful and uncomfortable arteriograms and $(b)$ all patients at increased risk-those who have had a previous severe adverse reaction to radiological contrast medium; those known to be allergic; those with asthma or diabetes; infants; patients with renal or cardiac impairment, myelomatosis, or sickle cell anaemia; and those who are very anxious. ${ }^{578}$

Both clinical and experimental evidence suggests that giving steroids by mouth (for example, $4 \mathrm{mg}$ dexamethasone) 12 and again two hours before injection substantially reduces the risk of an anaphylactoid reaction to conventional ionic radiological contrast media. ${ }^{59}$ If the cost of low osmolar radiological contrast media precludes their being given to all patients at increased risk, then administration of steroids should be carefully considered in asthmatic, allergic, or previous reactor patients if they are to be injected with conventional high osmolar radiological contrast media.

RONALD G GRAINGER

Professor in Radiodiagnosis,

University of Sheffield, and

Consultant Radiologist,

Royal Hallamshire Hospital, Sheffield S10 2JF

${ }^{1}$ Grainger RG. Intravascular radiological contrast media. The past, the present and the future. $\mathrm{Br}$ I Radiol 1982;55:1-18.

Grainger RG. Osmolality of intravascular radiological contrast media. Br $\mathcal{J}$ Radiol 1980;53:73946.

${ }^{3}$ Almén T. Contrast agent design. $\mathcal{F}$ Theor Biol 1969;24:216-26.

${ }^{4}$ Higgins CB. Effects of contrast materials on left ventricular function. Invest Radiol 1980;15, suppl:220-31.

Rapoport S, Bookstein JJ, Higgins CB, Carey PH, Sovak M, Lasser EC. Experience with metrizamide in patients with previous severe anaphylactoid reactions to ionic contrast agents. Radiology 1982;143:321-5.

${ }^{6}$ Webb JAW, Reznek RH, Catell WR, Fry IK. Renal function after high dose urography in patients with renal failure. Br 7 Radiol 1981;54:479-83.

Ansell G, Tweedie MCK, West CR, Evans DAP, Couch L. The
intravenous contrast media. Invest Radiol 1980;15, suppl:32-9.

${ }^{8}$ Lalli AF. Contrast media reactions; data analysis and hypothesis. Radiology 1980;134:1-12.

${ }^{9}$ Lasser EC. Radiology (in press).

\section{Night and day}

At least half the patients entering general surgical wards in a district general hospital are admitted as emergencies. ${ }^{12}$ By the time the family doctor has been consulted and transport arranged most of these admissions occur after normal working hours; $60 \%$ of patients needing emergency surgery reach the operating theatre between $6 \mathrm{pm}$ and midnight, and $17 \%$ between midnight and $8 \mathrm{am}$. Thus three quarters of emergency surgery is carried out after most people have finished work-a fact which is familiar to every surgeon but which has received less attention than it deserves.

At the end of a full day's operating older surgeons may reasonably feel thankful that their younger and perhaps stronger colleagues will generally undertake these nocturnal duties, just as they themselves did as juniors. It is indeed essential that surgeons in training should take a full share in the care of emergency patients. The surgery of the acute abdomen is one of the few remaining disciplines in which the general surgeon is considered to be a specialist, so it is vital that junior surgeons should receive a wide and well planned training. Training is the word which must be emphasised because the unsocial hours during which most 
emergency operating is done has meant that much of it has been unsupervised.

This custom was established when the keynote of emergency surgery was to do the least necessary to ensure survival, but the past 20 years have seen growing recognition of the value of a major definitive operation performed at emergency surgery. This move was pioneered in the 1930s by such masters of surgery as Yudin and Finsterer, who successfully undertook emergency gastrectomy for bleeding and perforated.peptic ulcers. ${ }^{34}$ In the 1950 s primary resection of the obstructed and perforated colon was shown to be effective and safe ${ }^{56}$ and in the 1960 s definitive treatment of the ruptured aortic aneurysm became the rule.

Contemporary senior registrars regard these operations as standard procedures. They have been trained by consultants who have come to recognise that (when carried out by experienced surgeons and anaesthetists) these definitive procedures offer patients a better prospect than the conventional lesser operations-for example, simple suture of perforated gastric ulcers and three stage treatment of neoplastic obstruction of the left colon. ${ }^{7}$ The corollary is that highly trained surgeons should be available to undertake emergency surgery at night. This may, however, be difficult to arrange, especially in the smaller district hospitals which employ only two consultant general surgeons, both of whom have a full daytime workload. (In this connection it seems strange that the argument, so strongly advanced, that junior staff should not be on duty more than one day in three does not seem to apply to consultants.)

Surgeons are a tough race and may consider loss of sleep to be a small price to pay for the sight of a patient making a good recovery from a serious emergency, but the interests of patients must be reconciled with the need for the surgical team to undertake reasonable hours of work.

So what may be done to ease the emergency load at night so that experienced surgeons have the time and energy to undertake such work in addition to their routine during the day? The arguments in favour of increasing the number of consultants (to improve among other things the care of emergencies) have been deployed for long enough. ${ }^{8} \mathrm{~A}$ better level of junior staff training and experience would come from adopting a more rational arrangement for the distribution of registrars from both home and overseas. ${ }^{8}$

Expansion of the consultant grade is still delayed despite the support of the Social Services Committee of the House of Commons ${ }^{9}$ and of the royal colleges. ${ }^{11}{ }^{11}$ To provide better emergency consultant cover it is unnecessary (and undesirable) to go to the lengths of introducing a shift system ${ }^{9}$ or expecting consultants to sleep in while on call. ${ }^{12}$ These suggestions, which can only deter consultants from pressing for expansion, must be dropped. Furthermore, only $30 \%$ of patients admitted as surgical emergencies need urgent surgery, and, as Sherlock and his colleagues have shown, as many as one third of these urgent operations, currently performed at night, may safely be left until the next day (p 170). Staff should not have to work at night only because an operating theatre is not available for emergency work during the day.

One of the tasks to which the National Health Service, as opposed to private medicine, is particularly committed is the provision of a high level of emergency care, and all the necessary skills in clinical, laboratory, and radiological services are concentrated in district hospitals. Many emergency operations are relatively simple and play an important part in training junior surgeons, but recent developments in resuscitation, anaesthesia, intensive care, and in major definitive operations for surgical emergencies require a higher level of skill. Provided that this is available gravely ill patients, especially the elderly, may make a quick and full recovery from clinical states that were previously fatal or the cause of long stays in hospital. It is not reasonable to expect willing but relatively inexperienced surgeons in training to undertake this type of surgery.

There are, therefore, compelling reasons for expanding the number of surgical consultants, not the least being the length of waiting lists and the very long hours of work required of many consultants. A major additional reason is that many skilled surgical registrars and senior registrars are ready to move into positions of greater responsibility. They are attuned to the recent developments in emergency surgery and could bring to out of hours emergency work the level of skill which it often requires.

Peter F Jones

Clinical Professor of Surgery,

University of Aberdeen,

Royal Aberdeen Children's Hospital,

Aberdeen AB9 2ŻG

Gilmore OJA, Griffiths NJ, Connolly JC, et al. Surgical audit: comparison of the work load and results of two hospitals in the same district. Br Med F 1980;281:1050-2.

${ }^{2}$ Stower MJ, Hardcastle JD, Bourke JB. Surgical emergencies and manpower. Ann R Coll Surg Engl 1984;66:117-9,

Yudin S. Étude sur les ulcères gastriques et duodénaux perfores. Foumal Internat Chirurgica 1939;4:219-25.

Finsterer H. Surgical treatment of acute profuse gastric hemorrhage. Surg Gynecol Obstet 1939, 69:291-8.

Baronofsky ID. Primary resection and aseptic end to end anastomosis for acute and subacute large bowel obstructions. Surgery 1950;27:664-72.

${ }^{6}$ Ryan P. Emergency resection and anastomosis for perforated sigmoid diverticulitis. $\mathrm{Br} f$ Surg $1958 ; 46: 611-6$.

Valerio D, Jones PF. Immediate resection in the treatment of large bowel emergencies. Br $\mathcal{F}$ Surg

1978;65:712-6.
Jones PF. Problems and solutions in the selection, training, and organisation of hospital surgical staff. Br Med J 1969;iii:464-6.

(1) Medical education with special reference to the of doctors and the career structure in hospitals. London: HMSO, 1981. (Short report.)

(a) College of Surgeons of Edinburgh. Career structure in surgery: implications for manpover and training. Edinburgh: Royal College of Surgeons of Edinburgh, 1980

training. Edinburgh: Royal College of Surgeons of Edinburgh, 1980.
Royal College of Surgeons of England. Report on surgical manpower and the career structure.

London: Royal College of Surgeons of England, 1981.

12 Stride R. Consultants' leaders reject live-in posts. Hospital Doctor 1984 April 12:20.

\section{Metabolic consequences of bilateral nephrectomy}

Bilateral nephrectomy is seldom performed routinely nowadays but it may be indicated for some patients with end stage renal failure who are having maintenance dialysis. Current dialysis techniques take over the excretory role of the kidneys and help in the control of salt and water balance but they cannot replace the renal endocrine functions entirely. Erythropoietin, for example, may be secreted by the kidneys even in advanced uraemia, and anephric patients often become severely anaemic and respond poorly to treatment with haematinics. ${ }^{1}$ These patients may require frequent blood transfusions-with the consequent risk of iron overload.

The influence of bilateral nephrectomy on calcium and vitamin $\mathrm{D}$ metabolism has been more difficult to determine. The recent development of sensitive radioimmunoassays for vitamin $\mathrm{D}$ and its metabolites has shown that the kidney is of crucial importance in the conversion of vitamin $\mathrm{D}_{3}$ to its active metabolites. Vitamin $D_{3}$ may be obtained from the diet or from photoconversion of 7-dehydrocholesterol in the skin and it undergoes several metabolic steps before its full biological potential is achieved. ${ }^{2}$ Firstly, it is metabolised by a hepatic microsomal enzyme to $25(\mathrm{OH}) \mathrm{D}_{3}$. This step is substrate limited, so that serum concentrations of $25(\mathrm{OH}) \mathrm{D}_{3}$, broadly reflect the vitamin $\mathrm{D}$ in the diet. The 